\title{
A 21st Century Manifesto for the end of business as usual
}

\author{
SURESH SOOD \\ University of Technology Sydney, Australia
}

At the end of last century in 1999, the Cluetrain Manifesto (cluetrain.com) messages herald the end of business as usual for companies discovering the web and point corporates strongly towards the notion "markets are conversations". Over a decade later, companies are participating in business online but are still none the wiser this century when trying to deal with connected customers as real people and often have no long term plans for social media activities. In light of this, the End of Business as Usual is not only a timely book in 2012 but also a potential compass for business leaders and communications professionals feeling disorientated by the proliferation of social media technologies. Of course, some might rightly believe "business as usual is an oxymoron" (a hat tip for the book publication by Hugh MacLeod of gapingvoid).

Over some 300 pages comprising 20 chapters, Brian Solis presents a veritable gold mine of information. The challenge for the reader is to recognise this book is two books not one. At one level, the book is densely packed with demographic and market research information providing support for the existence of a connected society and a lifestyle amongst Generation $\mathrm{C}$, a new type of consumer transcending all age groups. You probably even agree with this thinking if you already live life online. This thinking is very much in line with Solis as sociologist conveying the societal impacts of new media and makes for valuable reading for students, business executives and PR professionals. At another level, Solis has written a book providing thought leadership for c-level executives. Unlike other publications in the category "social media”, Solis is not button pushing or taking us through the virtues of Google Plus versus Twitter. Instead, he assumes we live with the tools and technologies of social media and focuses on the big picture strategy and what we do with the tools. This approach makes an ideal read for business leaders.

If one is critical about the book, the end of the story deserves exploration from the first page turn, not just the last 3 chapters. At the end of the book, Solis provides a future state for businesses, a blueprint to "rewire the way you work to succeed in the consumer revolution". Perhaps the desire through the dizzying array of research is to shock readers to move to a worldview of "always on" mobile devices and "the new point of purchase" (Google refers to this as the zero moment of truth) whereby today's businesses are paralysed and incapable of succeeding without change. Solis unravels an ideal framework for the leaders of business to understand how to build a business to resonate within a connected society. He guides the evolution of organisations from the traditional rigid silo organisations to a customer-centric adaptive and ultimately a predictive business. This future vision mandates a shift away from strategic plans to businesses creating "magical and shareable customer experiences" with connected customers. This change impacts not only the leadership team but has profound implications for culture intruding on all departments inclusive of customer service, marketing, product development and sales. Marc Benioff, CEO of the marketing juggernaut Salesforce.com refers to the change as the "corporate spring" whereby employees and customers alike are in the midst of overthrowing the rigid business model of traditional big companies. For example, Sensis the Australian organisation providing White and Yellow pages since 1880 proclaims a future organisation delivering a great experience for customers. The Sensis products face obsolescence with Facebook acting as "the personal operating 
system" with consumers using the social network to locate content and navigate to other sites. The reviews and social check-ins of consumers provides greater visibility for local businesses over the Yellow pages. Solis is absolutely spot on with the changes taking place amongst brand owners and the future evolution of organisations.

Some businesses fail to change and Solis contends suffer from "Digital Darwinism" when society and technology evolve faster than the company ability to adapt or exploit the situation. Such companies are "terminally ill” or "deceased". Fairfax and News Ltd unable to meet the requirements of connected consumers. Yet, Facebook is the newspaper of choice for a billion users on the planet. Further, Solis sees the future of media as social integrating into our lives when "the medium is no longer the message" but incorporates real people within television shows (e.g. X-factor) through incorporating news tweets. Already, the writing is on the wall for broadcast television with YouTube a major destination for entertainment.

The foundation upon which Solis builds his thesis requires familiarity from all communications professionals to understand social media interactions are not under the control of the business and take place in real time through connected consumers. Hence, he devotes much space to discussion and figures illustrating "nicheworks" (networks within networks), "one to many publishing” (social graphs), one-to-one-to-many (interest graphs) and ego-networks (self interest social graphs). The networking discussion helps explain Google circles and Facebook Groups as grouping of friends by interest and relationship and not just for gossiping. In the same vein, he constructs a model of privacy as a process of boundary management. Albeit briefly, Solis places the onus on the consumer not the social network provider with respect to sharing information, "privacy is by all means in our control to define how much other people know about us, what they see, and the impressions they form”.

Solis has a writing style not only attributable to his immense knowledge of social media but he has an uncanny knack of capturing much of the highlights of this book through homilies. Highly recommended is acquiring a hard copy of the book and working with a highlighter to capture these gems. Chapter 4 on attention deficit and information scarcity serves as a case in point with "If you don't have anything interesting or productive don't say it" or Chapter 8 convergence, the intersection of media and the human network explains "shared experiences are shared online, creating a new type of influential water cooler effect".

In the 21st century, the actions connected consumers take generate a data stream embedding social signals (tweet, blog, status updates and even GPS data). These individual life streams grow exponentially with each and every new source of data and represent individual personalities made public. This is the one area Solis still requires to explore, the implications of online personalities but probably forms the subject of a future book. Without a doubt, Solis has written a great book covering a wealth of information but above all provides businesses with the blueprint to conducting business online with real connected people not market segments. 